\title{
HIGHER BMI IN INFANCY ASSOCIATES WITH OVERWEIGHT AND HIGHER BODY ADIPOSITY IN EARLY CHILDHOOD: A COHORT STUDY IN TAIWAN
}

Tzu-Hsiang Weng $^{1,2 *}$, Po-Hsiang Kao ${ }^{1,2}$, Yu-Wen Huang ${ }^{1,2}$, Yin-Shan Huang ${ }^{1,2}$, Hsin Fang ${ }^{1,3}$, Ching-Hua Lin ${ }^{1,3}$, Zhao-Ting Tsai $^{1,2}$, Chun-Chun Gau ${ }^{1}$, Wan-Fang Lee ${ }^{1}$, Hui-Ju Tsai ${ }^{4}$, Tsung-Chieh Yao ${ }^{1,2}$

${ }^{1}$ Department of Pediatrics, Chang Gung Memorial Hospital, Taoyuan, Taiwan

${ }^{2}$ Department of Medicine, Chang Gung University College of Medicine, Taoyuan, Taiwan

${ }^{3}$ School of Traditional Chinese Medicine, Chang Gung University College of Medicine, Taoyuan, Taiwan ${ }^{4}$ Institute of Population Health Sciences, National Health Research Institutes, Miaoli, Taiwan

Background and Aims: Body mass index (BMI) in infancy has been reported as a predictor for childhood obesity as defined by BMI in some studies. However, the relationship between BMI in infancy and body adiposity in childhood remains unclear. The aim of this study was to investigate whether BMI in infancy is a predictor for higher BMI and body adiposity at 6 years of age in a population-based cohort study of Taiwanese children.

Study design: This cohort study included 613 Taiwanese children ( 345 boys, $56.3 \%$ ). BMI data was collected at 6 months, 12 months, 18 months and 6 years of age. A child's weight status (overweight or normal weight) was defined by International Obesity Task Force cut-offs. We also measured percentage of total body fat and percentage of central body fat at 6 years of age.

Table 1. Sample characteristics

\begin{tabular}{|l|l|l|}
\hline Characteristic & $\begin{array}{l}\text { Normal weight } \\
\text { at } 6 \text { years of age }\end{array}$ & $\begin{array}{l}\text { Overweight at } 6 \\
\text { years of age }\end{array}$ \\
\hline $\mathbf{N}$ & 520 & 92 \\
\hline $\begin{array}{l}\text { Gender, } \mathbf{n} \\
\text { (male/female) }\end{array}$ & $284 / 236$ & $60 / 32$ \\
\hline $\begin{array}{l}\text { BMI at birth } \\
\text { (means } \pm S D)\end{array}$ & $12.62 \pm 1.52$ & $13.03 \pm 2.36$ \\
\hline $\begin{array}{l}\text { BMI at 6 months* } \\
\text { (means } \pm S D)\end{array}$ & $17.70 \pm 2.02$ & $18.35 \pm 2.16$ \\
\hline $\begin{array}{l}\text { BMI at 12 months* } \\
\text { (means } \pm S D)\end{array}$ & $16.95 \pm 1.60$ & $17.60 \pm 1.77$ \\
\hline $\begin{array}{l}\text { BMI at 18 months* } \\
\text { (means } \pm S D \text { ) }\end{array}$ & $17.36 \pm 1.40$ & $17.36 \pm 1.93$ \\
\hline $\begin{array}{l}\text { BMI at 6 years* } \\
\text { (means } \pm S D \text { ) }\end{array}$ & $15.37 \pm 0.94$ & $19.61 \pm 1.94$ \\
\hline
\end{tabular}

*P-value $<0.05$
Results: Children with overweight at 6 years had a higher mean $\mathrm{BMI}$ at 6 months $(P=0.024), 12$ months $(P=0.005)$, and 18 months $(P=0.001)$, compared to those with normal weight at 6 years. BMl at 6 months $(P=0.006), 12$ months $(P<0.001)$, and 18 months $(P<0.001)$ was significantly associated with $\mathrm{BMI}$ at 6 years. In addition, $\mathrm{BMI}$ at 6 months, 12 months, and 18 months was also significantly associated with both percentage of total body fat (PBF) and percentage of central body fat (central PBF) at 6 years (all $P<0.001$ ). We then evaluate whether PBF and central PBF could be used to define adiposity at 6 years of age.
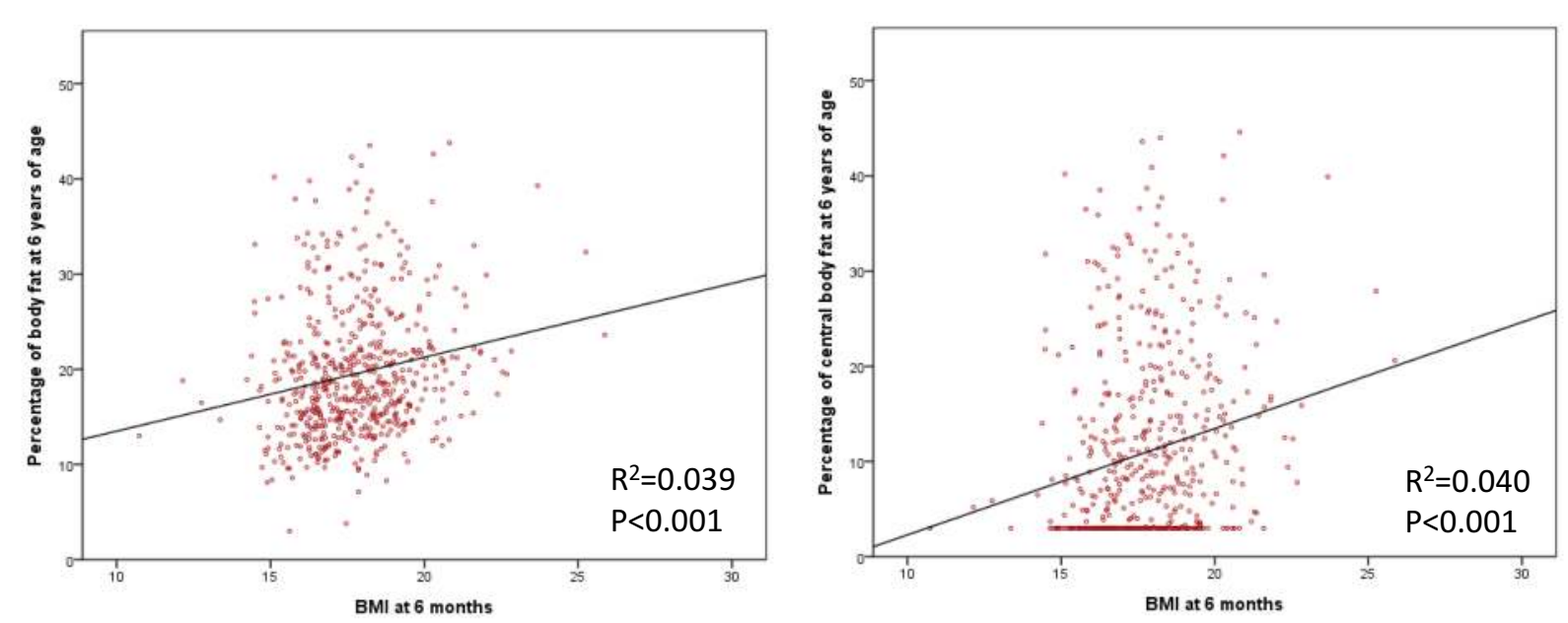

Figure 1. Relationship of body composition at 6 years of age to BMI at 6 months

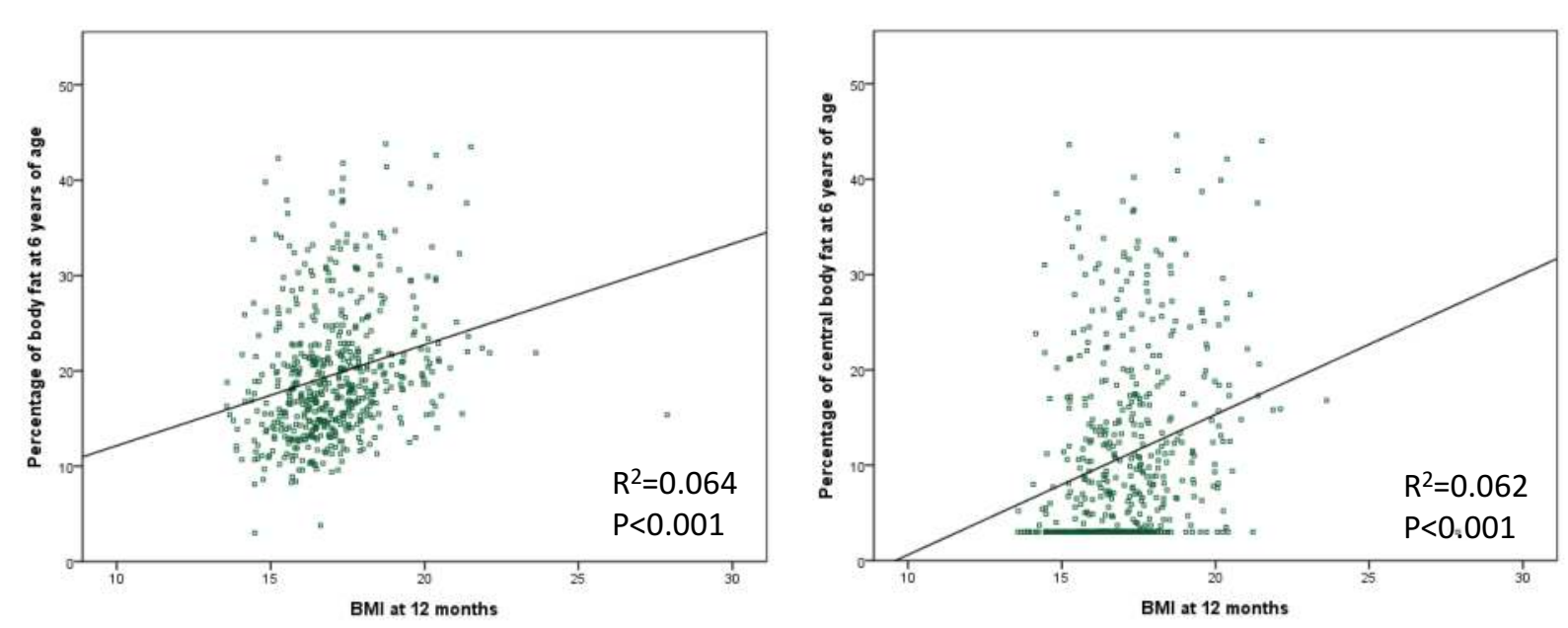

Figure 2. Relationship of body composition at 6 years of age to BMI at 12 months

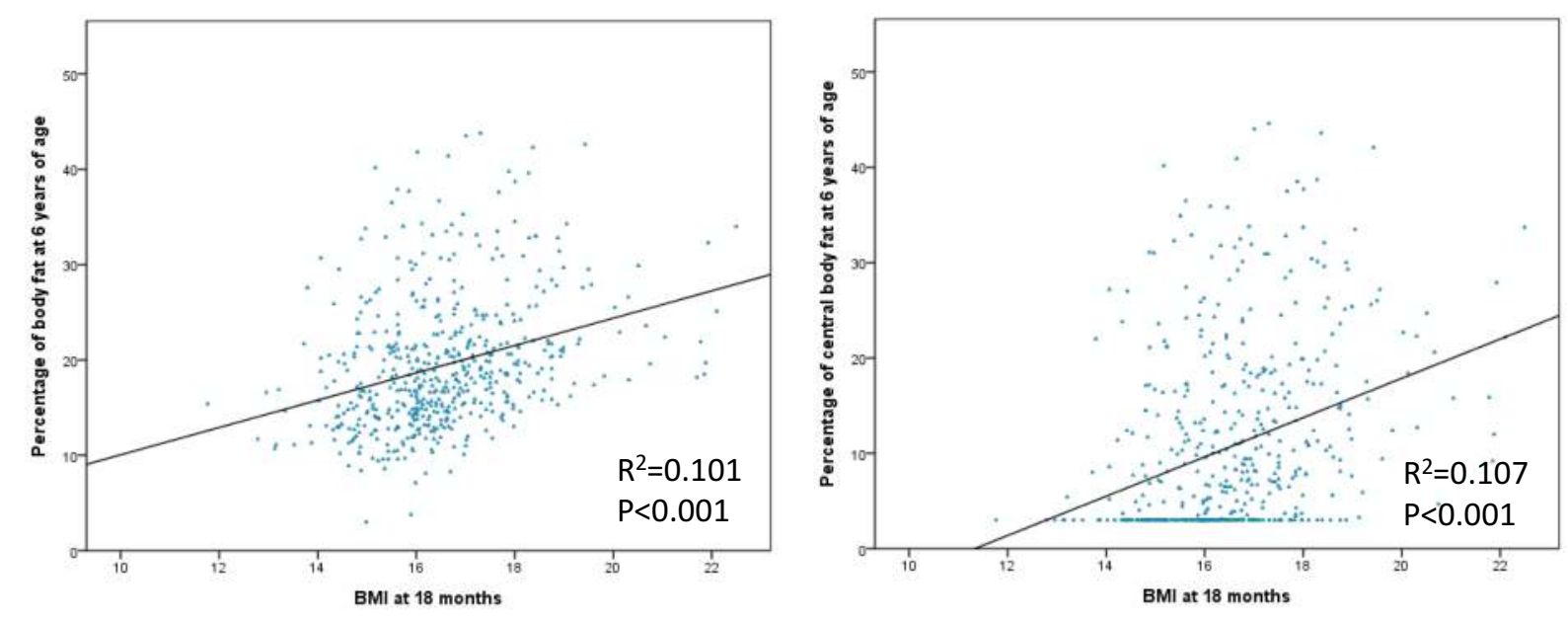

Figure 3. Relationship of body composition at 6 years of age to BMI at 18 months

Conclusion: Our study indicates that higher BMI in infancy may predict overweight and higher body adiposity in early childhood. Further studies are needed to confirm the findings in this study. 